\title{
PELATIHAN AKUNTANSI DAN WIRAUSAHA PENGELOLA BANTUAN DAN PENERIMA BANTUAN PROGRAM JALIN MATRA PENANGGULANGAN KERENTANAN KEMISKINAN PROVINSI JAWA TIMUR TAHUN 2016 DI DESA KAIBON KECAMATAN GEGER KABUPATEN MADIUN
}

\author{
Nanang Cendriono ${ }^{1)}$, Titin Eka Ardiana ${ }^{2)}$, Wahna Widhianingrum ${ }^{3)}$ \\ ${ }^{1,2,3}$ Fakultas Ekonomi Universitas Muhammadiyah Ponorogo \\ Email: ${ }^{1}$ nanangcendriono@gmail.com, ${ }^{2}$ titin_ardiana@yahoo.co.id, ${ }^{3}$ wwahna@yahoo.com
}

\begin{abstract}
Implementation of Poverty Matriculation Mitigation (PK2) Program in Kaibon Village, Geger Sub-district, Madiun District is a model of pilot activity in the framework of testing the process and the result of the activity so that it can be known the level of effectiveness and improvement efforts on the implementation of programs or activities that are larger and spacious. The objectives of community service at Jalin Matra PK2 Program in Kaibon Village are: (a) To encourage vulnerable villagers of Kaibon Village to be able to overcome their own vulnerability based on local social-economic potential in their village; (b) Encourage the vulnerable community of Kaibon Village to conduct productive economic activities based on the local socio-economic potential of the village, and (c) Encouraging the growth and development of Kaibon Village to be able to manage community empowerment activities, poverty alleviation and village economics. The target of community devotion of Jalin Matra Penanggulangan PK2 Program in Kaibon Village is target household (RTS) of PK2 beneficiaries and BUMDDa Kaibon village PK2 aid managers whose value is Rp. 100,000,000 received by East Java Provincial Government in 2016 through Jalin Matra Program. The selected target audience is the member of BUMDesa and the Beneficiary of Jalin Matra PK2 of Kaibon Village, Geger Sub-district, Madiun Regency, amounting to 17 people. The dedication to beneficiaries PK2 and BUMDDa Kaibon Jalin Matra beneficiaries include (1) Training Accounting to BUMDesa Kaibon as a fund manager of Jalin Matra PK2 Rp. 100.000.000, - (2) Entrepreneurship training for PK2 loan beneficiaries in Kaibon village, and (3) Submission of marketing technique of PK2 Program recipient business in Kaibon Village, Geger District, Madiun District. The result of Community Service at Jalin Matra PK2 Program in Kaibon Village is the training activity was held on 22 September 2017 at 15.30 WIB, located in Kaibon Village, Geger Sub-district, Madiun Regency. Participants of the training are members of BUMDesa and Recipients of the Constituents of Constituent of Kayu Matra PK2 of Kaibon Village totaling 17 people. So the conclusion after the accounting and entrepreneurship training activities for members of BUMDesa and beneficiaries of Jalin Matra PK2 Desa Kaibon to improve the financial performance of village government and business activities for beneficiaries in order to run smoothly. All participants enthusiastically attended the event to completion and felt the benefits of training for the progress of their business.
\end{abstract}

Keywords: Improvement of Herbal Medicine Business, Jalin Matra Program Beneficiary

Abstrak. Pelaksanaan Program Jalin Matra Penanggulangan Kerentanan Kemiskinan (PK2) di Desa Kaibon, Kecamatan Geger, Kabupaten Madiun adalah sebagai model kegiatan percontohan dalam rangka pengujian proses maupun hasil kegiatan sehingga dapat diketahui tingkat efektifitas serta upaya-upaya perbaikan pada implementasi program atau kegiatan yang skalanya lebih besar dan luas. Tujuan pengabdian masyarakat pada Program Jalin Matra PK2 di Desa Kaibon antara lain: (a) Mendorong masyarakat rentan Desa Kaibon agar mampu mengatasi kerentanannya sendiri berdasarkan pada potensi sosial ekonomi lokal di desanya, (b) Mendorong agar masyarakat rentan Desa Kaibon mampu melakukan kegiatan ekonomi produktif berdasarkan pada potensi sosial ekonomi lokal di desanya, dan (c) Mendorong tumbuh dan berkembangnya BUMDesa Kaibon supaya mampu mengelola kegiatan pemberdayaan masyarakat, penanggulangan kemiskinan dan perekonomian desa. Sasaran pengabdian masyarakat Program Jalin Matra Penanggulangan PK2 di Desa Kaibon adalah rumah tangga sasaran (RTS) penerima bantuan PK2 dan BUMDesa Kaibon pengelola bantuan PK2 yang nilainya Rp. 100.000.000,- yang menerima dari Pemerintah Provinsi Jawa Timur pada tahun 2016 lewat Program Jalin Matra. Khalayak sasaran yang dipilih adalah anggota BUMDesa dan Penerima Bantuan Jalin Matra PK2 Desa Kaibon, Kecamatan Geger, Kabupaten Madiun yang berjumlah 17 orang. Adapun pengabdian terhadap penerima bantuan PK2 dan BUMDesa Kaibon penerima bantuan Jalin Matra meliputi (1) Pelatihan Akuntansi kepada BUMDesa Kaibon sebagai pengelola dana bantuan Jalin Matra PK2 yang nilainya Rp. 100.000.000,- (2) Pelatihan wirausaha terhadap penerima pinjaman PK2 di desa Kaibon, dan 
(3) Penyampaian Teknik pemasaran usaha penerima pinjaman Program PK2 di Desa Kaibon Kecamatan Geger Kabupaten Madiun. Hasil dari Pengabdian Masyarakat pada Program Jalin Matra PK2 di Desa Kaibon adalah Kegiatan pelatihan ini dilaksanakan pada tanggal 22 September 2017 waktu pukul 15.30 WIB, yang bertempat di Desa Kaibon, Kecamatan Geger, Kabupaten Madiun. Peserta pelatihan adalah anggota BUMDesa dan Penerima Bantuan Jalin Matra PK2 Desa Kaibon yang berjumlah 17 orang. Sehingga kesimpulannya setelah kegiatan pelatihan akuntansi dan kewirausahaan bagi anggota BUMDesa dan penerima bantuan Jalin Matra PK2 Desa Kaibon untuk meningkatkan kinerja keuangan pemerintahan desa dan kegiatan usaha bagi penerima bantuan agar bisa berjalan dengan lancar. Semua peserta antusias mengikuti acara hingga selesai dan merasakan manfaat pelatihan bagi kemajuan usaha mereka.

Kata kunci : Peningkatan Usaha Jamu, Penerima Bantuan Program Jalin Matra

\section{PENDAHULUAN}

Wilayah Desa Kaibon sangat luas disamping itu pada wilayah ini mayoritas adalah petani dan mempunyai potensi pertanian yang tinggi. Adapun potensi yang lain yaitu terbagi dalam aneka kerajinan keramik bermutu tinggi seperti teh, guci, gelas, cangkir, mug dan lepek dan sudah terkenal di masyarakat. Selain usaha tersebut juga banyak masyarakat Desa Kaibon mempunyai usaha buka warung sembako, usaha jual jajanan, usaha warung kopi, usaha mlijo, dan ada yang usaha ternak.

Dengan banyaknya usaha tersebut tentunya masyarakat desa Kaibon banyak yang membutuhkan modal usaha. Kebanyakan masyarakat desa Kaibon pinjam modal usaha di bank, koperasi dan bahkan banyak yang pinjam di Bank Perkreditan Rakyat yang bunganya sangat tinggi. Dengan adanya Program Jalin Matra PK2 sangat membantu masyarakat Desa Kaibon dalam meningkatkan usahanya karena BUMDesa bunganya sangat ringan.

Permasalahan kemiskinan

keseluruhan menjadi perhatian Pemerintah Provinsi Jawa Timur, namun secara khusus membidik kelompok rumah tangga yang berada pada desil 2 dan desil 3 atau mereka yang berada dalam dalam kategori kelompok Rumah Tangga Hampir Miskin (RTHM). Secara sederhana, kelompok masyarakat yang rentan menjadi miskin lazim digambarkan sebagai kelompok masyarakat yang rapuh, ringkih dan tidak memiliki kemampuan dalam menghadapi berbagai tekanan sosial dan ekonomi yang melanda kehidupannya seperti adanya kenaikan harga barang kebutuhan sehari-hari (sembako), kebutuhan untuk pengobatan anggota keluarga yang sakit, terjadinya gagal panen, adanya bencana alam, dan berbagai tekanan lain yang berkaitan dengan kelangsungan hidup mereka.

Melalui Jalin Matra PK2 Tahun Anggaran 2016 ini, Pemerintah Provinsi Jawa Timur tetap berkomitmen untuk menolong kelompok masyarakat rentan yang berada pada desil 2 dan 3 agar tidak terperosok ke dalam jurang kemiskinan atau kelompok desil 1 . Berdasarkan data PPLS 2011, jumlah rumah tangga di Provinsi Jawa Timur yang berada pada desil 2 sebesar 1.189.670 rumah tangga atau sebesar 3.932.347 jiwa, jumlah pada desil 3 sebesar 1.189.652 rumah tangga atau sebesar 3.527.666 jiwa. Secara keseluruhan berjumlah 2.379.322 rumah tangga atau 7.460.013 jiwa tersebut menjadi sasaran pelaksanaan Jalin Matra Penanggulangan Kerentanan Kemiskinan (PK2) tahun 2016.

Secara esensial RTHM yang berada di desil 2 dan 3 adalah rumah tangga yang dalam kesehariannya sebenarnya relatif cukup mampu dalam mencukupi kebutuhannya, tetapi jika ada kebutuhan lain yang lebih mendesak, mereka akan mengalami kesulitan dalam memenuhinya.

$$
\text { Desa Kaibon Kecamatan Geger }
$$

kabupaten madiun merupakan salah satu desa yang menerima bantuan program jalin matra PK2 tahun 2016, berdasarkan Basis Data Terpadu (BDT) Tim Nasional Percepatan Penanggulangan Kemiskinan (TNP2K) memiliki rumah tangga yang masuk ke dalam kategori desil 2 dan 3 minimal 100 rumah tangga, Desa Kaibon juga memiliki potensi sumber daya alam yang dapat dikembangkan, Desa Kaibon telah memiliki Profil desa dan melakukan entri data di website profil Desa, Desa Kaibon juga memiliki BUMDesa dan atau berpotensi membentuk BUMDesa. 
Pengelolaan keuangan menjadi salah satu aspek penting bagi kemajuan perekonomian masyarakat desa. Pengelolaan keuangan dapat dilakukan melalui akuntansi. Akuntansi merupakan proses sistematis untuk menghasilkan informasi keuangan yang dapat digunakan untuk pengambilan keputusan bagi penggunanya. Akuntansi akan memberikan beberapa manfaat bagi Badan Usaha Milik Desa (BUMDesa) khususnya di desa Kaibon, Kecamatan Geger, Kabupaten Madiun antara lain: (1) Badan Usaha Milik Desa (BUMDesa) dapat mengetahui kinerja keuangan masyarakat desa, (2) Badan Usaha Milik Desa (BUMDesa) dapat mengetahui, memilah, dan membedakan harta bantuan dana dari pemerintah provinsi Jawa Timur dan harta penerima bantuan PK2, (3) Badan Usaha Milik Desa (BUMDesa) dapat mengetahui posisi dana baik sumber maupun penggunaannya, (4) Badan Usaha Milik Desa (BUMDesa) dapat membuat anggaran yang tepat, (5) Badan Usaha Milik Desa (BUMDesa) dapat menghitung pajak, dan (6) Badan Usaha Milik Desa (BUMDesa) dapat mengetahui aliran uang tunai selama periode tertentu.

Adapun pengabdian terhadap penerima bantuan PK2 dan BUMDesa Kaibon penerima bantuan Jalin Matra meliputi (1) Pelatihan Akuntansi kepada BUMDesa Kaibon sebagai pengelola dana bantuan Jalin Matra PK2 yang nilainya Rp. 100.000.000,- (2) Pelatihan wirausaha terhadap penerima pinjaman PK2 di desa Kaibon, dan (3) Penyampaian Teknik pemasaran usaha penerima pinjaman Program PK2 di Desa Kaibon Kecamatan Geger Kabupaten Madiun.

\section{METODE PELAKSANAAN}

Lokasi kegiatan pengabdian masyarakat adalah di Desa Kaibon Kecamatan Geger Kabupaten Madiun Provinsi Jawa Timur. Sasaran pengabdian adalah Pengelola Program Jalin Matra PK2 lewat BUMDesa dan penerima pinjaman di Desa Kaibon Kecamatan Geger Kabupaten Madiun.

Sasaran 17 orang tersebut merupakan sasaran dari Jalin Matra PK2 mengacu pada data PPLS 2011. Dengan bantuan Program Jalin Matra Penanggulangan Kerentanan Kemiskinan
Propinsi Jawa Timur 2016 akan mengadakan Pengabdian masyarakat terhadap rumah tangga sasaran (RTS) penerima bantuan PK2 dan BUMDesa Kaibon pengelola bantuan PK2 yang nilainya Rp. 100.000.000,- yang menerima dari Pemerintah Provinsi Jawa Timur pada tahun 2016 lewat Program Jalin Matra.

Adapun pengabdian terhadap penerima bantuan PK2 dan BUMDesa Kaibon penerima bantuan Jalin Matra meliputi :

1. Pelatihan Akuntansi kepada BUMDesa Kaibon sebagai pengelola dana bantuan Jalin Matra PK2 yang nilainya Rp. 100.000.000,-

2. Pelatihan wirausaha terhadap penerima pinjaman PK2 di desa Kaibon Kecamatan Geger Kabupaten Madiun.

3. Penyampaian Teknik pemasaran usaha penerima pinjaman Program PK2 di Desa Kaibon Kecamatan Geger Kabupaten Madiun.

\section{HASIL DAN PEMBAHASAN}

Kabupaten Madiun adalah sebuah kabupaten di Provinsi Jawa Timur Indonesia. Kabupaten ini berbatasan dengan Kabupaten Bojonegoro di utara, Kabupaten Nganjuk di timur, Kabupaten Ponorogo di selatan serta Kabupaten Magetan dan Ngawi di barat. Ibukota adalah Kecamatan Mejayan sesuai dengan Peraturan Pemerintah No.52 Tahun 2010.

Desa Kaibon Kecamatan Geger kabupaten madiun merupakan salah satu desa yang menerima bantuan program jalin matra PK2 tahun 2016, berdasarkan Basis Data Terpadu (BDT) Tim Nasional Percepatan Penanggulangan Kemiskinan (TNP2K) memiliki rumah tangga yang masuk ke dalam kategori desil 2 dan 3 minimal 100 rumah tangga, Desa Kaibon juga memiliki potensi sumber daya alam yang dapat dikembangkan, Desa Kaibon telah memiliki Profil desa dan melakukan entri data di website profil Desa, Desa Kaibon juga memiliki BUMDesa dan atau berpotensi membentuk BUMDesa.

Dalam kegiatan pengabdian masyarakat disini, Khalayak sasaran yang dipilih adalah anggota BUMDesa dan Penerima Bantuan Jalin Matra PK2 Desa Kaibon, Kecamatan Geger, Kabupaten Madiun yang berjumlah 17 orang. Penetapan sasaran ini merupakan suatu upaya 
untuk meningkatkan kinerja keuangan Badan Usaha Milik Desa (BUMDesa) dan penerima bantuan untuk mengelola usaha yang tergolong pada usaha kecil dan menengah dan masih belum mempunyai kemampuan menyusun laporan keuangan sesuai standar yang ada. sehingga perkembangannya dapat diketahui dan dipantau dengan mudah. Lebih jauh dari itu, harapannya peserta pelatihan dapat menularkan ilmu yang didapatkan kepada Badan Usaha Milik Desa (BUMDesa) dan penerima bantuan yang berada di sekitarnya.

Program pelatihan ini dilaksanakan atas kerjasama Universitas Muhammadiyah Ponorogo dengan anggota BUMDesa dan Penerima Bantuan Jalin Matra PK2 Desa Kaibon, Kecamatan Geger, Kabupaten Madiun. Kegiatan pelatihan ini dilaksanakan pada tanggal 22 September 2017 waktu pukul 15.30 WIB, yang bertempat di Desa Kaibon, Kecamatan Geger, Kabupaten Madiun. Peserta pelatihan adalah anggota BUMDesa dan Penerima Bantuan Jalin Matra PK2 Desa Kaibon, Kecamatan Geger, Kabupaten Madiun yang berjumlah 17 orang.

Pelaksanaan kegiatan pengabdian ini diawali dengan koordinasi dengan pihak anggota BUMDesa Jalin Matra PK2 Desa Kaibon, Kecamatan Geger, Kabupaten Madiun, yang disambut dengan baik dan didukung oleh para pengurusnya. Selanjutnya panitia pelaksana menentukan jadwal dan tempat pelaksanaan kegitan pelatihan. Langkah berikutnya yang dilakukan adalah menyebarkan surat undangan kepada masing-masing anggota BUMDesa dan Penerima Bantuan Jalin Matra PK2 Desa Kaibon, Kecamatan Geger, Kabupaten Madiun. Setelah diberikan jangka waktu tertentu, para peserta memberikan konfirmasi kesediaan mengikuti kegiatan ini disertai nama peserta masingmasing. Sebelumnya panitia pelaksana telah berkoordinasi dengan nara sumber atas kesediaannya sebagai nara sumber pada kegiatan ini.

Sebelum pelaksanaan kegiatan pengabdian ini diawali dengan koordinasi dengan pihak anggota BUMDesa Jalin Matra PK2 Desa Kaibon, Kecamatan Geger, Kabupaten Madiun selain juga koordinasi tentang dana bantuan yang diperoleh yaitu dari dana bantuan Program Jalin Matra PK2 Provinsi Jawa Timur Tahun 2016. Berikut tabel penjelasan aliran dana bantuan Program Jalin Matra PK2 Provinsi Jawa Timur Tahun 2016 tentang Rekapitulasi Laporan Penggunaan Dana dan Bantuan Pinjaman Rumah Tangga Sasaran serta Biaya Operasional Desa Kaibon, Kecamatan Geger, Kabupaten Madiun

Tabel 1. Program Jalin Matra PK2 Provinsi Jawa Timur Tahun 2016 Rekapitulasi Laporan Penggunaan Dana Desa Kaibon, Kecamatan Geger, Kabupaten Madiun

\begin{tabular}{|c|c|c|c|c|c|}
\hline No & Tanggal & Uraian kegiatan & Penerimaan & Pengeluaran & Saldo \\
\hline 1 & $20 / 07 / 2016$ & $\begin{array}{l}\text { Terima dana kegiatan Program } \\
\text { Jalin Matra(PK2) dari } \\
\text { Gubernur Jawa Timur melalui } \\
\text { Bank Jatim }\end{array}$ & Rp. 100.000.000,- & - & Rp. 100.000.000,- \\
\hline 2 & $30 / 07 / 2016$ & $\begin{array}{l}\text { Dipindah bukukan dana usaha } \\
\text { simpan pinjam RTS dari } \\
\text { rekening desa ke rekening } \\
\text { BUMDesa melalui Bank Jatim }\end{array}$ & - & Rp. 90.000.000,- & Rp. 10.000.000,- \\
\hline 3 & $01 / 08 / 2016$ & Dicairkan dana BOP Program & - & Rp. 10.000.000,- & 0 \\
\hline & & Jumlah & Rp. 100.000.000,- & Rp. 100.000.000,- & $\mathbf{0}$ \\
\hline
\end{tabular}

Sumber: Program Jalin Matra PK2 Provinsi Jawa Timur Tahun 2016, Desa Kaibon, Kecamatan Geger, Kabupaten Madiun

Tabel 2. Tabel Bantuan Pinjaman Rumah Tangga Sasaran dan Biaya Operasional

\begin{tabular}{llclcl}
\hline No & Uraian & Volume & Satuan & Harga satuan (Rp) & Jumlah (Rp) \\
\hline 1 & Bantuan Pinjaman Pokmas Dahlia 1 & 1 & Pokmas & $15.000 .000,00$ & $15.000 .000,00$ \\
\hline 2 & Bantuan Pinjaman Pokmas Dahlia 2 & 1 & Pokmas & $15.000 .000,00$ & $15.000 .000,00$ \\
\hline 3 & Bantuan Pinjaman Pokmas Teratai 1 & 1 & Pokmas & $15.000 .000,00$ & $15.000 .000,00$ \\
\hline 4 & Bantuan Pinjaman Pokmas Teratai 2 & 1 & Pokmas & $15.000 .000,00$ & $15.000 .000,00$ \\
\hline
\end{tabular}




\begin{tabular}{lllccc}
\hline 5 & Bantuan Pinjaman Pokmas Melati 1 & 1 & Pokmas & $15.000 .000,00$ & $15.000 .000,00$ \\
\hline 6 & Bantuan Pinjaman Pokmas Melati 2 & 1 & Pokmas & $15.000 .000,00$ & $15.000 .000,00$ \\
\hline 7 & Biaya Operasional Sekretariat Desa & - & - & $4.250 .000,00$ & $4.250 .000,00$ \\
\hline 8 & Biaya Operasional Kegiatan & - & - & $5.750 .000,00$ & $5.750 .000,00$ \\
\hline
\end{tabular}

Sumber: Program Jalin Matra PK2 Provinsi Jawa Timur Tahun 2016, Desa Kaibon, Kecamatan Geger, Kabupaten Madiun

Pada pelaksanaan pengabdian tentang pelatihan ini dirasakan sangat bermanfaat bagi peserta pelatihan. Koordinasi dan kerjasama yang dilakukan antara anggota BUMDesa dan Penerima Bantuan Jalin Matra PK2 Desa Kaibon, Kecamatan Geger, Kabupaten Madiun sudah sangat baik. Pihak anggota BUMDesa dan Penerima Bantuan Jalin Matra PK2 Desa Kaibon, Kecamatan Geger, Kabupaten Madiun, sangat menyambut kegiatan yang dapat meningkatkan kemampuan para anggotanya melalui kerja sama dengan pihak Universitas Muhammadiyah Ponorogo, terutama yang berkaitan dengan pendidikan dan pelatihan.

Namun terdapat beberapa hal yang dapat menjadi masukan bagi pelaksana kegiatan ini, yaitu jumlah peserta yang diundang kurang dapat memenuhi harapan, mereka mengharapkan kegiatan seperti ini hendaknya dapat dilakukan dengan peserta yang lebih banyak dari saat ini, karena kegiatan ini sangat penting untuk meningkatkan profesionalisme bagi mereka yang bergerak di bidang akuntansi. Jika dilihat dari undangan yang disebarkan, sebenarnya kehadiran peserta saat pelatihan sangat baik, yaitu telah mencapai 95\%, hal ini menunjukkan bahwa sasaran kegiatan ini sangat antusias mengikuti pelaksanaan kegiatan yang dilakukan ini.

\section{SIMPULAN DAN SARAN}

\section{Simpulan}

Kegiatan pelatihan akuntansi dan kewirausahaan bagi anggota BUMDesa dan penerima bantuan Jalin Matra PK2 Desa Kaibon, Kecamatan Geger, Kabupaten Madiun untuk meningkatkan kinerja keuangan pemerintahan desa dan kegiatan usaha bagi penerima bantuan agar bisa berjalan dengan lancar. Semua peserta antusias mengikuti acara hingga selesai dan merasakan manfaat pelatihan bagi kemajuan usaha mereka.

\section{Saran}

Pelatihan serupa dapat dilaksanakan kembali dengan peserta (audience) yang lebih banyak atau luas, dan dengan topik lainnya. Di samping itu fasilitas untuk presentasi seperti LCD, pengeras suara sebaiknya diperiksa kembali sebelum acara dilaksanakan.

\section{DAFTAR PUSTAKA}

Anonim. 2016. www.madiunkab.go.id

Anonim. 2016. Info madiun. Kondisi ekonomi kabupaten madiun.com

Bapemas Provinsi Jawa Timur. (2016) Pedoman Umum Penanggulangan Kerentanan Kemiskinan. Pemerintah Provinsi Jawa Timur. Surabaya.

Handoko. 2009. Statistik Kesehatan, Belajar Mudah Teknik Analisis Data dalam Penelitian Kesehatan. Mitra Cendekia Press. Jakarta. 